\title{
Estimation of soil moisture using trapezoidal relationship between remotely sensed land surface temperature and vegetation index
}

\author{
W. Wang, D. Huang, X.-G. Wang, Y.-R. Liu, and F. Zhou \\ State Key Laboratory of Hydrology-Water Resources and Hydraulic Engineering, Hohai University, Nanjing, 210098, China \\ Received: 26 October 2010 - Published in Hydrol. Earth Syst. Sci. Discuss.: 3 November 2010 \\ Revised: 23 May 2011 - Accepted: 24 May 2011 - Published: 30 May 2011
}

\begin{abstract}
The trapezoidal relationship between land surface temperature $\left(T_{\mathrm{s}}\right)$ and Vegetation Index (VI) was used to estimate soil moisture in the present study. An iterative algorithm is proposed to estimate the vertices of the $T_{\mathrm{S}} \sim \mathrm{VI}$ trapezoid theoretically for each pixel, and then Water Deficit Index (WDI) is calculated based on the $T_{\mathrm{S}} \sim \mathrm{VI}$ trapezoid using MODIS remotely sensed measurements of surface temperature and enhanced vegetation index (EVI). The capability of using WDI based on $T_{\mathrm{s}} \sim$ VI trapezoid to estimate soil moisture is evaluated using soil moisture observations and antecedent precipitation in the Walnut Gulch Experimental Watershed (WGEW) in Arizona, USA. The result shows that, the $T_{\mathrm{S}} \sim$ VI trapezoid based WDI can capture temporal variation in surface soil moisture well, but the capability of detecting spatial variation is poor for such a semi-arid region as WGEW.
\end{abstract}

\section{Introduction}

In the 1980's, it was found that, land surface temperature $\left(T_{\mathrm{S}}\right)$ and the fraction of vegetation cover, which is represented by Vegetation Indices (VI), e.g., Normalized Difference Vegetation Index (NDVI), typically show a strong negative relationship (e.g., Goward et al., 1985; Nemani and Running, 1989). Such a relationship has been widely used to investigate the moisture condition of land surfaces. Several studies focused on the slope of the $T_{\mathrm{s}} / \mathrm{NDVI}$ curve for providing information on vegetation and moisture conditions at the surface (e.g., Smith and Choudhury, 1991; Nemani et al., 1993). Their approach was later extended to use the information in the

Correspondence to: $\mathrm{W}$. Wang

(w.wang@126.com)
$T_{\mathrm{S}} / \mathrm{VI}$ scatter-plot space, whose envelope is considered to be in either a triangular shape (e.g., Price, 1990; Carlson et al., 1994), or a trapezoid shape (e.g., Moran et al., 1994).

The idea of a triangle in the $T_{\mathrm{s}} / \mathrm{VI}$ space has been used to develop the so called "triangle method", and has been applied by many researchers for estimating soil moisture and evapotranspiration (see Carlson, 2007). The central assumption of the triangle method is that, given a large number of pixels reflecting a full range of soil surface wetness and fractional vegetation cover, sharp boundaries (edges) in the data scatter plot reflect real physical limits: i.e., bare soil, $100 \%$ vegetation cover, and lower and upper limits of the surface soil water content, e.g., completely dry or wet (field capacity), respectively. The dry and wet edges ultimately intersect at a (truncated) point at full vegetation cover. Then, based on the triangle, the relative value of surface soil water content and the surface energy fluxes at each pixel can be defined in terms of its position within the triangle. The advantage of the triangle method is its independence of ancillary data. The approach, however, has difficulty in defining the dry and wet edge, especially the dry edge. Even with a large number of remotely sensed observations, the boundaries of the triangle space are still hard to establish, because on one hand, there are situations when $T_{\mathrm{s}} \sim \mathrm{VI}$ points scatter in a narrow range such as during rainy season or in areas with a narrow VI range; on the other hand, the $T_{\mathrm{s}} \sim$ VI relationship is much more complicated at large scale than at local scale and may vary at different parts due to heterogeneity in land surface properties and atmospheric forcing. Furthermore, as the triangle space is established empirically, the soil moisture estimates according to such an empirical triangle based on an image at one time are hard to be compared with those at another time. 
Moran et al. (1994) proposed the idea of vegetation index/temperature (VIT) trapezoid for describing the relationship between the surface temperature and air temperature difference $\left(T_{\mathrm{s}}-T_{\mathrm{a}}\right)$ vs. the fractional vegetation cover $\left(V_{\mathrm{C}}\right)$, and developed the Water Deficit Index (WDI) for evaluating evapotranspiration rates of both full-cover and partially vegetated sites. However, although the idea of VIT trapezoid is well accepted, very few applications were found in the literature based on the idea of VIT trapezoid for estimating soil moisture, partly because of the difficulty in calculating $T_{\mathrm{S}}-T_{\mathrm{a}}$, partly because of the limitation of meteorological data requirements. In the present paper, we aim to simplify the idea of VIT trapezoid to $T_{s} \sim$ VI trapezoid, and propose an iterative algorithm for quantifying the shape of the $T_{\mathrm{S}} \sim \mathrm{VI}$ trapezoid, then estimate soil moisture based on the $T_{\mathrm{S}} \sim \mathrm{VI}$ trapezoid. The method of establishing the $T_{\mathrm{S}} \sim \mathrm{VI}$ trapezoid will be described in detail in Sect. 2. Then the method will be applied to the Walnut Gulch Experimental Watershed in Arizona, USA, for which, the data used and data pre-processing will be described in Sects. 3 and 4, and the results will be presented in Sect. 5. Finally, some conclusions will be drawn in Sect. 6.

\section{Trapezoid method}

\subsection{The concept of $\left(T_{\mathrm{s}}-T_{\mathrm{a}}\right) \sim V_{\mathrm{C}}$ trapezoid}

Idso et al. (1981) and Jackson et al. (1981) proposed the CWSI (Crop Water Stress Index) for detecting plant water stress based on the difference between canopy and air temperature. It is designed for full-cover vegetated areas and bare soils at local and regional scales. To overcome the difficulty of measuring foliage temperature in partially vegetated fields, Moran et al. (1994) proposed to use the shape of trapezoid to depict the relationship between the surface temperature and air temperature difference $\left(T_{\mathrm{s}}-T_{\mathrm{a}}\right)$ vs. the fractional vegetation cover $\left(V_{\mathrm{C}}\right.$, ranging from 0 for bare soil to 1 for full-cover vegetation) (Fig. 1), so as to combine spectral vegetation indices with composite surface temperature measurements to allow application of the CWSI theory to partially vegetated fields without a priori knowledge of the percent vegetation cover.

Based on the trapezoid assumption and the CWSI theory, Moran et al. (1994) introduced the Water Deficit Index (WDI) for evaluating field evapotranspiration rates and relative field water deficit for both full-cover and partially vegetated sites. For a given pixel with measured surface temperature and air temperature difference, i.e., $\left(T_{\mathrm{s}}-T_{\mathrm{a}}\right)_{\mathrm{r}}$, WDI is defined as:

$\mathrm{WDI}=\frac{\left(T_{\mathrm{s}}-T_{\mathrm{a}}\right)_{\min }-\left(T_{\mathrm{s}}-T_{\mathrm{a}}\right)_{\mathrm{r}}}{\left(T_{\mathrm{s}}-T_{\mathrm{a}}\right)_{\min }-\left(T_{\mathrm{s}}-T_{\mathrm{a}}\right)_{\max }}$

where $T_{\mathrm{a}}$ is air temperature; $T_{s}$ is surface temperature; the subscripts min, max, and $r$ refer to minimum, maximum, and

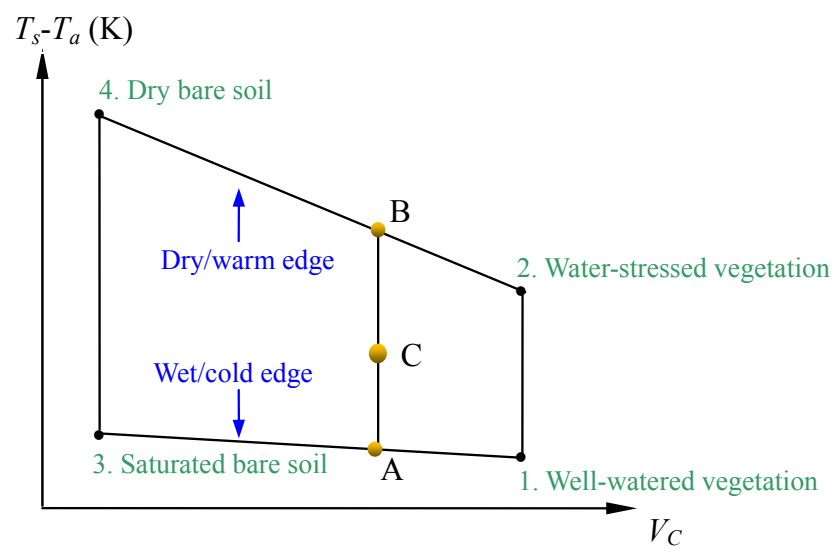

Fig. 1. The hypothetical trapezoidal shape based on the relation between $\left(T_{\mathrm{S}}-T_{\mathrm{a}}\right)$ and the fractional vegetation cover $\left(V_{\mathrm{C}}\right)$.

measured values, respectively; and the minimum and maximum values of $\left(T_{\mathrm{s}}-T_{\mathrm{a}}\right)$ are interpolated linearly on the cold edge and warm edge of the $\left(T_{\mathrm{s}}-T_{\mathrm{a}}\right) \sim V_{\mathrm{C}}$ trapezoid for the specific $V_{\mathrm{C}}$ value of the pixel. Graphically, WDI is equal to the ratio of distances $\mathrm{AC} / \mathrm{AB}$ in Fig. 1.

\subsection{Calculation of vertices of the $\left(T_{\mathrm{S}}-T_{\mathrm{a}}\right) \sim V_{\mathrm{C}}$ trapezoid and its simplification: the $T_{\mathrm{s}} \sim \mathrm{VI}$ trapezoid}

The theoretical basis of $\left(T_{\mathrm{S}}-T_{\mathrm{a}}\right) \sim V_{\mathrm{C}}$ trapezoid is the energy balance equation, i.e.,

$R_{\mathrm{n}}=G+H+\lambda E$

where, $R_{\mathrm{n}}$ is the net radiant heat flux density $\left(\mathrm{W} \mathrm{m}^{-2}\right), G$ is the soil heat flux density $\left(\mathrm{W} \mathrm{m}^{-2}\right), H$ is the sensible heat flux density $\left(\mathrm{W} \mathrm{m}^{-2}\right)$, and $\lambda E$ is the latent heat flux to the air $\left(\mathrm{W} \mathrm{m}^{-2}\right)$ and $\lambda$ the heat of vaporization of water $\left(\mathrm{kJ} \mathrm{kg}^{-1}\right)$.

In their simplest forms, $H$ can be estimated with a bulk transfer equation written in the form (Monteith and Unsworth, 2008):

$H=C_{\mathrm{v}}\left(T_{\mathrm{s}}-T_{\mathrm{a}}\right) / r_{\mathrm{a}}$

and $\lambda E$ can be expressed as

$\lambda E=\left[\Delta\left(R_{\mathrm{n}}-G\right)+C_{\mathrm{v}}(\mathrm{VPD}) / r_{\mathrm{a}}\right] /\left[\Delta+\gamma\left(1+r_{\mathrm{c}} / r_{\mathrm{a}}\right)\right]$

where

- $T_{\mathrm{S}}$ and $T_{\mathrm{a}}$ are the surface temperature and air temperature $(\mathrm{K})$, respectively;

- $C_{\mathrm{v}}$ is the volumetric heat capacity of air $\left(1295.16 \mathrm{~J} \mathrm{~K}^{-1} \mathrm{~m}^{-3}\right)$;

- VPD (vapor pressure deficit of the air) (hPa) is calculated as a difference between saturation vapour pressure 
$e_{\mathrm{S}}$ and actual vapour pressure $e_{\mathrm{a}}(\mathrm{hPa})$, given by (WMO, 2008)

$e_{\mathrm{S}}=6.112 \exp \left(\frac{17.62 T_{\mathrm{a}}^{\prime}}{T_{\mathrm{a}}^{\prime}+243.12}\right)$

( $T_{\mathrm{a}}^{\prime}$ is the air temperature in $\left.{ }^{\circ} \mathrm{C}, T_{\mathrm{a}}^{\prime}=T_{\mathrm{a}}-273.15\right)$,

$e_{\mathrm{a}}=\mu e_{\mathrm{s}},(\mu$ is observed relative humidity $)$

- $\Delta$ is the slope of the curve of saturation water vapour pressure versus air temperature, calculated with (WMO, 2008)

$$
\Delta=4098 \cdot e_{\mathrm{s}} /\left(237.3+T_{\mathrm{a}}^{\prime}\right)^{2}
$$

- $\gamma$ the psychrometric constant $\left(\mathrm{hPa} \mathrm{k}^{-1}\right)$, given by

(WMO, 2008)

$\gamma=0.646+0.0006 T_{\mathrm{a}}^{\prime}$

- $r_{\mathrm{a}}$ the aerodynamic resistance to heat transfer $\left(\mathrm{s} \mathrm{m}^{-1}\right)$;

$-r_{\mathrm{c}}$ the canopy resistance to vapor transport $\left(\mathrm{s} \mathrm{m}^{-1}\right)$;

It should be noticed that, the usage of surface temperature $T_{\mathrm{s}}$, instead of aerodynamic temperature $T_{\text {aero }}$, in Eq. (3) may lead to some errors for calculating $H$ because the differences between $T_{\text {aero }}$ and $T_{\mathrm{s}}$ could range from $2{ }^{\circ} \mathrm{C}$ over uniform vegetation cover to $10^{\circ} \mathrm{C}$ for partially vegetated areas (Kustas and Norman, 1996). To solve this problem, the traditional approach consists in modifying the aerodynamic resistance $r_{a}$ by adding an extra resistance (e.g., Kustas et al., 1989), commonly expressed as a function of the friction velocity $u^{*}$ and the dimensionless bulk parameter $B^{-1}$, which is reflected in Eq. (10).

Then, combining Eqs. (2), (3), and (4), we obtain the equation for temperature difference between air and land surface:

$$
\begin{aligned}
& \left(T_{\mathrm{s}}-T_{\mathrm{a}}\right)=\left[r_{\mathrm{a}}\left(R_{\mathrm{n}}-G\right) / C_{\mathrm{v}}\right]\left\{\gamma\left(1+r_{\mathrm{c}} / r_{\mathrm{a}}\right) /\right. \\
& \left.\left[\Delta+\gamma\left(1+r_{\mathrm{c}} / r_{\mathrm{a}}\right)\right]\right\}-\mathrm{VPD} /\left[\Delta+\gamma\left(1+r_{\mathrm{c}} / r_{\mathrm{a}}\right)\right]
\end{aligned}
$$

As suggested by Moran et al. (1994), for the $\left(T_{\mathrm{s}}-T_{\mathrm{a}}\right) \sim V_{\mathrm{C}}$ trapezoid, its four vertices correspond to (1) well-watered full-cover vegetation, (2) water-stressed full-cover vegetation, (3) saturated bare soil, and (4) dry bare soil. Using the energy balance equations, Moran et al. (1994) computed the values of the four vertices of the trapezoid as the following:

1. For full-covered and well-watered vegetation (Point 1)

$$
\begin{aligned}
\left(T_{\mathrm{s}}-T_{\mathrm{a}}\right)_{1}=\left[r_{\mathrm{a}}\left(R_{\mathrm{n}}-G\right) / C_{\mathrm{v}}\right] \\
\\
\left\{\gamma\left(1+r_{\mathrm{cm}} / r_{\mathrm{a}}\right) /\left[\Delta+\gamma\left(1+r_{\mathrm{cm}} / r_{\mathrm{a}}\right)\right]\right\} \\
-\mathrm{VPD} /\left[\Delta+\gamma\left(1+r_{\mathrm{cm}} / r_{\mathrm{a}}\right)\right]
\end{aligned}
$$

where $r_{\mathrm{cm}}$ is the minimum canopy resistance, i.e., canopy resistance at potential evapotranspiration.
2. For full-covered vegetation with no available water (Point 2)

$$
\begin{aligned}
\left(T_{\mathrm{S}}-T_{\mathrm{a}}\right)_{2}=\left[r_{\mathrm{a}}\left(R_{\mathrm{n}}-G\right) / C_{\mathrm{v}}\right] \\
\\
\left\{\gamma\left(1+r_{\mathrm{c} x} / r_{\mathrm{a}}\right) /\left[\Delta+\gamma\left(1+r_{\mathrm{c} x} / r_{\mathrm{a}}\right)\right]\right\} \\
-\mathrm{VPD} /\left[\Delta+\gamma\left(1+r_{\mathrm{c} x} / r_{\mathrm{a}}\right)\right]
\end{aligned}
$$

where $r_{\mathrm{c} x}$, is the canopy resistance associated with nearly complete stomatal closure.

3. For saturated bare soil (Point 3), where canopy resistance $r_{\mathrm{c}}=0$, we have

$$
\begin{aligned}
\left(T_{\mathrm{s}}-T_{\mathrm{a}}\right)_{3} & =\left[r_{\mathrm{a}}\left(R_{\mathrm{n}}-G\right) / C-\mathrm{v}\right][\gamma(\Delta+\gamma)] \\
& -\operatorname{VPD} /(\Delta+\gamma)
\end{aligned}
$$

4. For dry bare soil (Point 4), where $r_{\mathrm{c}}=\infty$ (analogous to complete stomatal closure), and $\lambda E=0$, we have

$\left(T_{\mathrm{s}}-T_{\mathrm{a}}\right)_{4}=r_{\mathrm{a}}\left(R_{\mathrm{n}}-G\right) / C_{\mathrm{v}}$

The $\left(T_{\mathrm{s}}-T_{\mathrm{a}}\right) \sim V_{\mathrm{C}}$ trapezoid considers that relationship between $\left(T_{\mathrm{s}}-T_{\mathrm{a}}\right)$ and $V_{\mathrm{C}}$. Now we think about the issue in another way that, with a given value of $T_{\mathrm{a}}$, how $T_{\mathrm{s}}$ is related with $V_{\mathrm{C}}$. To analyze this $T_{\mathrm{S}} \sim V_{\mathrm{C}}$ relationship, we use Eqs. (6) $\sim(9)$ to calculate the $T_{\mathrm{S}}$ for the four extreme cases (or trapezoid vertices) by moving $T_{\mathrm{a}}$ in Eqs. (6) $\sim(9)$ to the right side of the equations. At the same time, $V_{\mathrm{C}}$ is replaced by a vegetation index (VI). So that, we modify the structure of the trapezoid, obtaining a simplified $T_{\mathrm{S}} \sim \mathrm{VI}$ trapezoid with the horizontal axis as the VI, and the vertical axis as $T_{\mathrm{s}}$. We therefore refer the algorithm proposed here to as $T_{\mathrm{s}}-\mathrm{VI}$ trapezoid method.

To obtain the values of $T_{\mathrm{S}}$ with Eq. (6) $\sim(9)$, we need to know $r_{\mathrm{a}}, r_{\mathrm{c}}$ (including $r_{\mathrm{cm}}$ and $r_{\mathrm{c} x}$ ), $R_{\mathrm{n}}, G$ for the four vertices separately, as shown in the following section.

\subsection{Calculation of the components in the formula for four vertices of $T_{\mathrm{s}} \sim$ VI trapezoid}

\subsubsection{Aerodynamic resistance $\left(r_{\mathrm{a}}\right)$}

The water vapor aerodynamic resistance $r_{\mathrm{a}}\left(\mathrm{s} \mathrm{m}^{-1}\right)$ can be estimated with the following equation (Thom, 1975):

$r_{\mathrm{a}}=\left[\ln \left(\frac{z-d}{z_{0 \mathrm{~m}}}\right)-\psi_{\mathrm{m}}\right]\left[\ln \left(\frac{z-d}{z_{0 \mathrm{~h}}}\right)-\psi_{\mathrm{h}}\right] / k^{2} u_{z}(10)$

where

- $z$ is the height (m) above the surface at which $u_{z}$ and $T_{\mathrm{a}}$ are measured (commonly $2 \mathrm{~m}$ ); 
- $u_{z}$ is wind speed $\left(\mathrm{m} \mathrm{s}^{-1}\right)$, which could be measured directly;

- $d$ is displacement height (m), given by $d=0.667 h$, and $h$ is the height of vegetation (Garratt, 1992), which should be given as an input.

$z_{0 \mathrm{~m}}$ is the roughness lengths for momentum $(\mathrm{m})$, given by $z_{0 \mathrm{~m}}=h / 8$ (Garratt, 1992). For bare soil surface, $z_{0 \mathrm{~m}}$ is commonly taken to be $0.01 \mathrm{~m}$ (Shuttleworth and Wallace, 1985).

- $z_{0 \mathrm{~h}}$ is the roughness lengths for heat $(\mathrm{m})$, given by

$$
z_{0 \mathrm{~h}}=z_{0 \mathrm{~m}} / \exp \left(k B^{-1}\right)
$$

Here, $k B^{-1}$ is a dimensionless parameter. Kustas et al. (1989) showed that $k B^{-1}$ is a linear function of the product of $u_{z}$ and $T_{\mathrm{s}}-T_{\mathrm{a}}$, given by

$k B^{-1}=S_{k B} \cdot u_{z} \cdot\left(T_{\mathrm{s}}-T_{\mathrm{a}}\right)$

where $S_{k B}$ is an empirical coefficient, which varies somewhere between 0.05 and 0.25 .

- $k$ is the von Karman constant $(k=0.41)$;

- $\psi_{\mathrm{h}}$ and $\psi_{\mathrm{m}}$ are the stability corrections for heat and momentum transfer (unitless). $\psi_{\mathrm{h}}$ and $\psi_{\mathrm{m}}$ are calculated differently depending on the atmospheric stability, which could be indicated by the Monin-Obukhov length $L$ (Monin and Obukhov, 1954), given by

$L=-\rho C_{\mathrm{p}} u_{*}^{3} T_{\mathrm{a}} /(k g H)$

where $g=9.8 \mathrm{~m} \mathrm{~s}^{-2}, \rho$ is the air density $\left(\mathrm{kg} \mathrm{m}^{-3}\right), C_{\mathrm{p}}$ the air specific heat at constant pressure $\left(1004 \mathrm{~J} \mathrm{~kg}^{-1} \mathrm{~K}^{-1}\right), u_{*}$ is the friction velocity defined by $u_{*}=\frac{k u_{z}}{\ln \left[z-d / z_{0 \mathrm{~m}}\right]-\psi_{\mathrm{m}}}$.

For neutral conditions $(L=0), \psi_{\mathrm{h}}=\psi_{\mathrm{m}}=0$.

For stable situations $(L>0)$, expressions of $\psi_{\mathrm{h}}$ and $\psi_{\mathrm{m}}$ are (Webb, 1970):

$\psi_{\mathrm{m}}=\psi_{\mathrm{h}}=-5(z-d) / L$

For unstable conditions $(L<0)$, expressions of $\psi_{\mathrm{h}}$ and $\psi_{\mathrm{m}}$ are (Paulson, 1970):

$\left\{\begin{array}{l}\psi_{\mathrm{m}}=2 \ln \left(\frac{1+x}{2}\right)+\ln \left(\frac{1+x^{2}}{2}\right)-2 \arctan (x)+\pi / 2 \\ \psi_{\mathrm{h}}=2 \ln \left(\frac{1+x^{2}}{2}\right)\end{array}\right.$

where $x=[1-16(z-d) / L]^{1 / 4}$.

\subsubsection{Net radiant heat flux density $\left(R_{n}\right)$}

Net radiation is defined as the difference between the incoming and outgoing radiation fluxes including both long- and shortwave radiation at the surface of Earth. Net radiant heat flux density $\left(R_{\mathrm{n}}\right)\left(\mathrm{W} \mathrm{m}^{-2}\right)$ can be expressed as (Brutsaert, 2005):

$R_{\mathrm{n}}=(1-\alpha) R_{\mathrm{s}}+\varepsilon_{\mathrm{s}} \varepsilon_{\mathrm{a}} \sigma T_{\mathrm{a}}^{4}-\varepsilon_{\mathrm{s}} \sigma T_{\mathrm{s}}^{4}$

where

- $\alpha$ is surface shortwave albedo, which is derived from MODIS product MCD43A3;

- $R_{\mathrm{S}}$ is solar radiation, estimated jointly by solar constant, solar inclination angle, geographical location and time of year, atmospheric transmissivity, ground elevation, etc. The basic formula for estimating $R_{\mathrm{S}}$ is (Zillman, 1972):

$$
R_{\mathrm{s}}=\frac{S_{0} \cos ^{2} \theta}{1.085 \cos \theta+e_{0}(2.7+\cos \theta) \times 10^{-3}+0.1}
$$

where $S_{0}$ is the solar constant at the atmospheric top $\left(1367 \mathrm{~W} \mathrm{~m}^{-2}\right), \theta$ the solar zenith angle, $e_{0}$ is the vapor pressure. In consideration of the effects of topography on the incident short-wave radiation $\left(R_{\mathrm{S}}\right)$, the solar zenith angle $(\theta)$ is corrected using Digital Elevation Model (DEM) data (Duffie and Beckman, 1991) with the following formula:

$$
\begin{aligned}
\cos \theta & =\sin (\delta) \sin (\varphi) \cos (s) \\
& -\sin (\delta) \cos (\varphi) \sin (s) \cos (r) \\
& +\cos (\delta) \cos (\varphi) \cos (s) \cos (\omega) \\
& +\cos (\delta) \sin (\varphi) \sin (s) \cos (r) \cos (\omega) \\
& +\cos (\delta) \sin (\gamma) \sin (s) \sin (\omega)
\end{aligned}
$$

where $\phi$ is the latitude (positive in the Northern Hemisphere); $s$ is the slope, and $r$ is the slope orientation, both derived from DEM; $\delta$ is solar declination, and $\omega$ solar hour angle, given by

$\delta=0.409 \sin (2 \pi \cdot \mathrm{DOY} / 365-1.39)$

$\omega=\frac{\pi}{12}(t-12)$

where DOY is the day of year, and $t$ is the time when the satellite Terra which carries MODIS pass over the region ( 10:30 a.m.). 
- $\varepsilon_{\mathrm{a}}$ is the atmospheric emissivity estimated as a function of vapor pressure, given by Iziomon et al. (2003) $\varepsilon_{\mathrm{a}}=1-0.35 \exp \left(-10 e_{\mathrm{a}} / T_{\mathrm{a}}\right)$.

$-\varepsilon_{\mathrm{S}}$ is the surface emissivity. There are MODIS land surface emissivity products (MOD11) for MODIS bands 31 and 32, i.e. $\varepsilon_{31}$ and $\varepsilon_{32}$. But for extreme cases, i.e., bare soil and full vegetation coverage, the direct use of there products are not appropriate. Instead, according to Synder et al. (1998), we set $\varepsilon_{\mathrm{s}}=0.93$ for bare soil, and $\varepsilon_{\mathrm{s}}=0.993$ for full vegetation coverage.

In our algorithm, $R_{\mathrm{n}}$ is not directly solved with the Eq. (16), because $T_{\mathrm{s}}$ is considered as an unknown variable. Instead, we replace the term $R_{\mathrm{n}}$ in Eqs. (6) $\sim(9)$ with the Eq. (16) respectively, so that we get four quartic equations for $T_{\mathrm{S}}$ at four vertices separately. Then the quartic equations are solved with the iterative algorithm which is shown later in Sect. 2.4 and Fig. 2, by doing so, all the values of $T_{\mathrm{S}}$ for the four vertices are obtained.

\subsubsection{Soil heat flux density $G$}

$G$ is normally considered to be linearly related to $R_{\mathrm{n}}$. Several studies have shown that the value of $G / R_{\mathrm{n}}$ typically ranges between 0.4 for bare soil and 0.05 for full vegetation cover (Choudhury et al., 1987). Idso et al. (1975) conducted some experiments investigating the impacts of water content on the net radiation $\sim$ soil heat flux relationship over bare soil surface, and showed that $G / R_{\mathrm{n}}$ ranges from 0.2 for wet bare soil to 0.5 for dry bare soil.

\subsubsection{Canopy resistance $\left(r_{c}\right)$}

Canopy resistance $\left(r_{\mathrm{c}}\right)$, including $r_{\mathrm{cm}}$ and $r_{\mathrm{c} x}$ that refer to the minimum and maximum canopy resistances respectively, should be calculated for Point 1 and Point 2. According to Moran et al. (1994), $r_{\mathrm{cm}}$ in Eq. (6) is calculated with $r_{\mathrm{sm}} / \mathrm{LAI}$ (LAI is the maximum possible leaf area index, $r_{\mathrm{sm}}$ is minimum stomatal resistance). $r_{\mathrm{c} x}$ in Eq. (7) is calculated with $r_{\mathrm{s} x} / \mathrm{LAI}\left(r_{\mathrm{s} x}\right.$ is maximum stomatal resistance).

Values of minimum and maximum stomatal resistance $\left(r_{\mathrm{sm}}\right.$ and $r_{\mathrm{s} x}$, respectively) are published for many agricultural crops under a variety of atmospheric conditions. Moran et al. (1994) suggested that, if values are not available, reasonable values of $r_{\mathrm{sm}}=25 \sim 100 \mathrm{~s} \mathrm{~m}^{-1}$ and $r_{\mathrm{s} x}=1000 \sim 1500 \mathrm{~s} \mathrm{~m}^{-1}$ will not result in appreciable error, we set $r_{\mathrm{sm}}=100 \mathrm{~s} \mathrm{~m}^{-1}$ and $r_{\mathrm{s} x}=1500 \mathrm{~s} \mathrm{~m}^{-1}$. As values of LAI of various vegetation types are mostly less than 8 (Scurlock et al., 2001), we set LAI $=8$. Therefore, we have $r_{\mathrm{cm}}=12.5 \mathrm{~s} \mathrm{~m}^{-1}$ and $r_{\mathrm{c} x}=187.5 \mathrm{~s} \mathrm{~m}^{-1}$.

\subsection{Iterative procedure for calculating $T_{\mathrm{s}}$}

Values of $T_{\mathrm{S}}$ for the four vertices are obtained by an iterative procedure for each pixel. An initial value of $r_{\mathrm{a}}$ is estimated

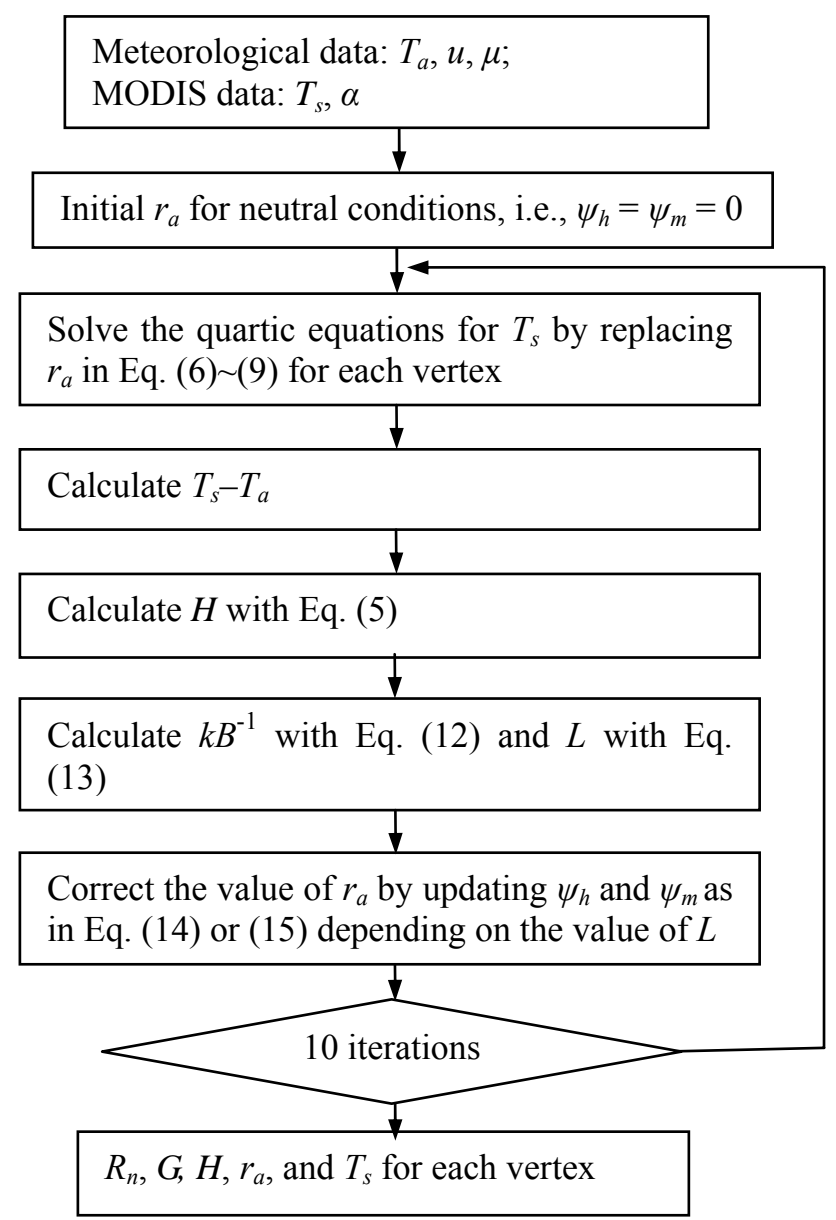

Fig. 2. Iterative procedure for calculating $T_{\mathrm{S}}$ of the four vertices of $T_{\mathrm{S}} \sim$ VI trapezoid.

by assuming neutral conditions, i.e., $\psi_{\mathrm{h}}=\psi_{\mathrm{m}}=0$. With the initial $r_{\mathrm{a}}$, initial values of $T_{\mathrm{S}}$ are obtained with Eq. (6) $\sim(9)$ for the four vertices. Then the iterative procedure is proceeded by iteratively changing $H, k B^{-1}, r_{\mathrm{a}}$, and in consequence, $T_{\mathrm{s}}$, until the value of $T_{\mathrm{S}}$ is stable (i.e., the change of $T_{\mathrm{S}}$ is less than $0.01 \mathrm{~K}$, and the change of $r_{\mathrm{a}}$ is less than $0.1 \mathrm{~s} \mathrm{~m}^{-1}$ ). Normally, it takes 5 to 10 iterations for $T_{\mathrm{s}}$ to get stable. However, there are cases in which $T_{\mathrm{S}}$ cannot reach a stable solution. In those cases, we use the $T_{\mathrm{S}}$ value of the first iteration. While $T_{\mathrm{s}}$ is derived, $R_{\mathrm{n}}, G, H$, and $r_{\mathrm{a}}$ for each vertex are obtained as well. When $T_{\mathrm{S}}$ is less than $T_{\mathrm{a}}$, we set $H=0$.

The iterative procedure is conducted pixel by pixel, that is, the trapezoid is constructed separately for each pixel, and each trapezoid has its own values of $T_{\mathrm{s}}$. 


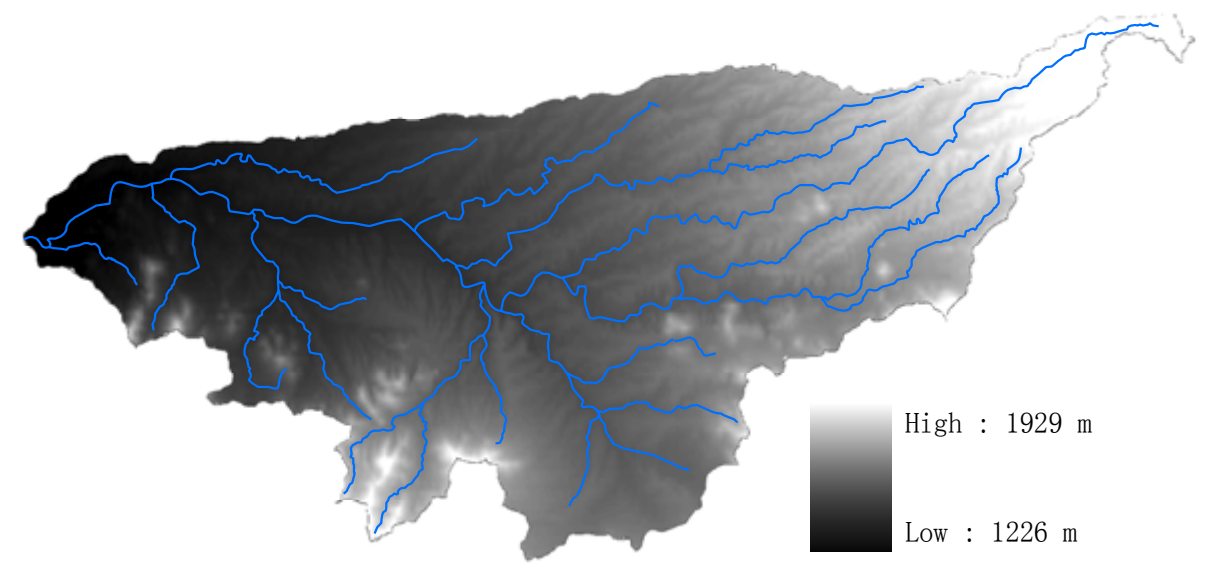

Fig. 3. Digital elevation model (DEM) of Walnut Gulch Experimental Watershed.

\section{Case study area and data used}

\subsection{The Walnut Gulch Experimental Watershed (WGEW)}

Data of the Walnut Gulch Experimental Watershed (WGEW) was used in the present study. The WGEW is defined as the upper $148 \mathrm{~km}^{2}$ of the Walnut Gulch drainage basin in an alluvial fan portion of the San Pedro catchment in southeastern Arizona (Fig. 3). It was developed as a research facility by the United States Department of Agriculture (USDA) in the mid-1950s. This rangeland region receives $250-500 \mathrm{~mm}$ of precipitation annually, with about two-thirds of it as convective precipitation during a summer monsoon season. The potential evapotranspiration is approximately ten times the annual rainfall. The topography can be described as gently rolling hills incised by steep drainage channels which are more pronounced at the eastern end of the catchment near the Dragoon Mountains. Soil types range from clays and silts to well-cemented boulder conglomerates, with the surface $(0-$ $5 \mathrm{~cm}$ ) soil textures being gravelly and sandy loams containing, on average, $30 \%$ rock and little organic matter (Renard et al., 1993). The mixed grass-brush rangeland vegetation ranges from 20 to $60 \%$ in coverage. Grasses primarily cover the eastern half of the catchment, while the western half is bush-dominated.

\subsection{MODIS data and ground observational data used}

The moderate resolution imaging spectroradiometer (MODIS) instrument has been widely used for monitoring soil moisture because of its high spectral (36 bands) resolution, moderate spatial $(250-1000 \mathrm{~m})$ resolution, and various products for land surface properties. All standard MODIS data products are freely available at NASA Land Processes Distributed Active Archive Center (URL: https://lpdaac.usgs.gov/lpdaac/). MODIS products used in the present study are listed in Table 1 . They are derived
Table 1. MODIS data used.

\begin{tabular}{|c|c|c|c|}
\hline $\begin{array}{l}\text { Product } \\
\text { ID }\end{array}$ & Contents & $\begin{array}{l}\text { Spatial } \\
\text { resolution }\end{array}$ & $\begin{array}{l}\text { Temporal } \\
\text { resolution }\end{array}$ \\
\hline MOD03 & Geolocation Data Set & $1 \mathrm{~km}$ & daily \\
\hline MOD11A1 & Surface Temperature & $1 \mathrm{~km}$ & daily \\
\hline MOD13A1 & Vegetation Indices & $500 \mathrm{~m}$ & 16 days \\
\hline MOD15A2 & Leaf Area Index & $1 \mathrm{~km}$ & 8 days \\
\hline MCD43A3 & Albedo & $500 \mathrm{~m}$ & 16 days* \\
\hline
\end{tabular}

*MCD43A3 product is produced every 8 days, using data from the last 16 days.

from the images of the MODIS sensor onboard Terra ( $\sim 10: 30$ a.m. overpass). We selected MODIS data of ten cloud-free days approximately evenly distributed in the period from January to December in 2004. All the $1 \mathrm{~km}$ resolution MODIS data are resampled to $500 \mathrm{~m}$ resolution with the nearest neighbor method. The reason of downscaling the $1 \mathrm{~km}$ resolution data to the $500 \mathrm{~m}$ resolution data is to keep more details with smaller pixel size.

Meteorological data required here include air temperature $T_{\mathrm{a}}$, relative humidity $\mu$, and wind velocity $u$, observed approximately at the time (11:00 a.m.) when the satellite Terra passes over the WGEW region. The $T_{a}$, relative humidity $\mu$, and wind velocity $u$, are observed at three sites. We take the average of the observations at 3 meteorological observation sites for $\mu$ and $u$. Observations of $T_{\mathrm{a}}$ are preprocessed, which will be discussed in Sect. 4.3. To evaluate the soil moisture estimation results, soil moisture observations at 16 sites and precipitation data at 87 sites are used. The locations of these sites are plotted in Fig. 4. As some gauging sites are located on the edge of the watershed, to include the observations at these sites for evaluation, our study area is slightly larger than WGEW. We used soil moisture observation data in 10 dates in 2004 when cloud-free MODIS data are available. All the soil moisture data are observed at 
Table 2. Statistics of surface soil moisture observations in 10 DOYs in 2004.

\begin{tabular}{|c|c|c|c|c|c|c|c|}
\hline \multirow[t]{2}{*}{ Site } & \multicolumn{3}{|c|}{ Soil moisture in 10 DOYs at each site } & \multirow[t]{2}{*}{ DOY } & \multicolumn{3}{|c|}{ Soil moisture at 16 sites in each DOY } \\
\hline & Mean $(\%)$ & $\mathrm{SD}(\%)$ & $\mathrm{CV}$ & & Mean $(\%)$ & $\mathrm{SD}(\%)$ & $\mathrm{CV}$ \\
\hline RG003 & 6.319 & 4.639 & 0.734 & 2 & 9.775 & 4.135 & 0.423 \\
\hline RG013 & 10.116 & 5.694 & 0.563 & 30 & 3.502 & 2.370 & 0.677 \\
\hline RG018 & 6.154 & 3.938 & 0.640 & 75 & 3.818 & 2.586 & 0.677 \\
\hline RG020 & 10.549 & 5.492 & 0.521 & 132 & 6.205 & 3.330 & 0.537 \\
\hline RG028 & 5.692 & 4.377 & 0.769 & 157 & 1.939 & 1.024 & 0.528 \\
\hline RG034 & 5.538 & 4.568 & 0.825 & 168 & 2.360 & 1.242 & 0.526 \\
\hline RG037 & 4.988 & 3.478 & 0.697 & 212 & 2.846 & 1.702 & 0.598 \\
\hline RG040 & 5.987 & 4.265 & 0.712 & 256 & 11.574 & 5.061 & 0.437 \\
\hline RG057 & 7.458 & 3.200 & 0.429 & 290 & 9.788 & 3.657 & 0.374 \\
\hline RG069 & 9.906 & 7.685 & 0.776 & 345 & 11.427 & 3.713 & 0.325 \\
\hline RG070 & 3.771 & 2.003 & 0.531 & & & & \\
\hline RG076 & 1.405 & 1.542 & 1.098 & & & & \\
\hline RG082 & 3.419 & 4.057 & 1.187 & & & & \\
\hline RG083 & 5.524 & 3.546 & 0.642 & & & & \\
\hline RG092 & 7.802 & 5.521 & 0.708 & & & & \\
\hline RG100 & 4.100 & 3.587 & 0.875 & & & & \\
\hline
\end{tabular}

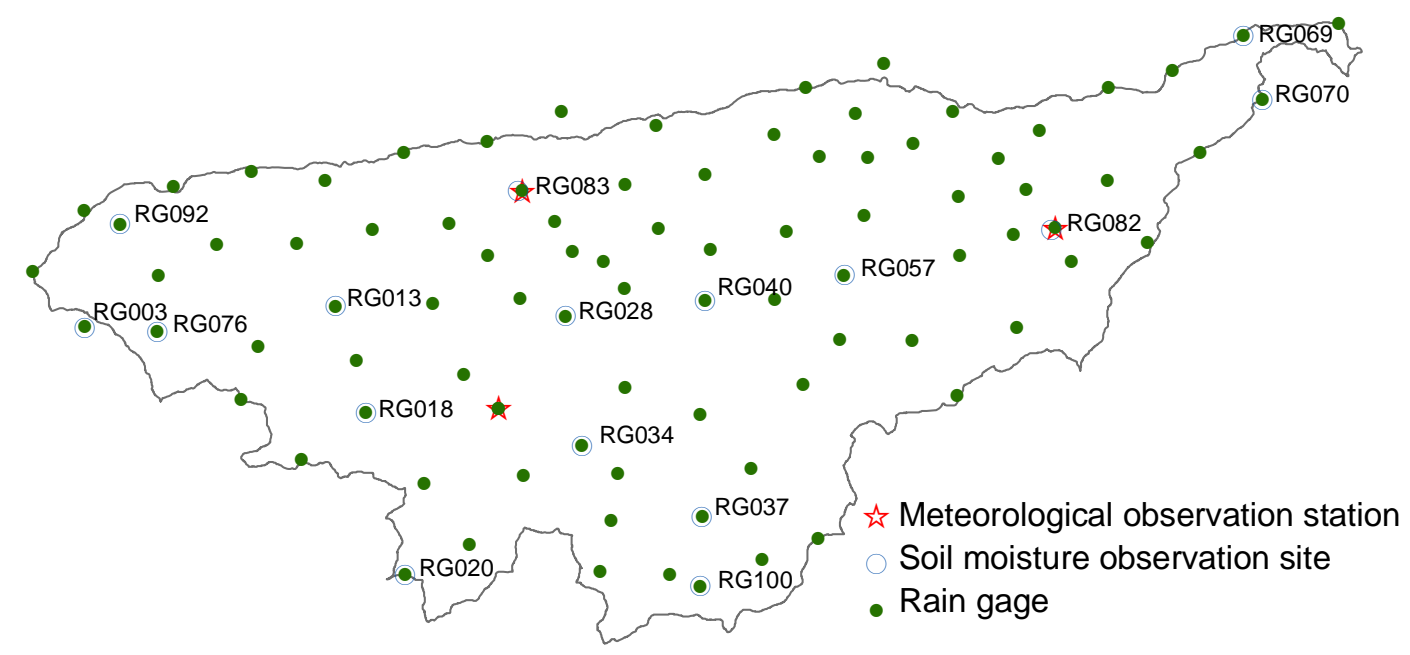

Fig. 4. Locations of ground-based observation sites in WGEW.

$5 \mathrm{~cm}$ below the surface. The statistics of the soil moisture observation we used are listed in Table 2.

All the ground-based observational data, including meteorological observations, soil moisture observations and land cover data are obtained from the website of United States Department of Agriculture (USDA) Southwest Watershed Research Center (URL: http://www.tucson.ars.ag.gov/dap/). In addition, SRTM Digital Elevation Model (DEM) data (URL: http://srtm.csi.cgiar.org/) are used.

\section{Data pre-processing}

\subsection{Denoising the MOD13A1 Vegetation Index data}

Vegetation Indices (VIs) are transformations of spectral reflectance of two or more bands designed to enhance the contribution of vegetation properties. Two commonly used VIs that are available as MODIS products are Normalized Difference Vegetation Index (NDVI) and Enhanced Vegetation Index (EVI), given by

$\mathrm{NDVI}=\frac{\left(\rho_{\mathrm{NIR}}-\rho_{\mathrm{red}}\right)}{\left(\rho_{\mathrm{NIR}}+\rho_{\mathrm{red}}\right)}$, 
and EVI $=\frac{2.5\left(\rho_{\mathrm{NIR}}-\rho_{\mathrm{red}}\right)}{\left(\rho_{\mathrm{NIR}}+6.0 \rho_{\text {red }}-7.5 \rho_{\text {blue }}+1\right)}$,

where $\rho_{\text {blue }}, \rho_{\text {red }}$, and $\rho_{\text {NIR }}$ represent reflectance at the blue $(0.45-0.52 \mu \mathrm{m})$, red $(0.6-0.7 \mu \mathrm{m})$, and Near-Infrared (NIR) $(0.7-1.1 \mu \mathrm{m})$ wavelengths, respectively. In the present study, EVI is used due to its less sensitivity to background reflectance variations (Liu and Huete, 1995). The MODIS EVI values varied from 0.07 to $\sim 0.7$ for major land cover types from hyperarid deserts to dense forests at $1-\mathrm{km}$ resolution (Huete et al., 2011).

The MODIS VI product attempts to retrieve cloud-free, near-nadir, top-of-canopy greenness at 16-day interval. However, due to the global nature of the algorithm, some problems and uncertainties persist at local scales, mostly associated with residual clouds, shadows, aerosols, atmospheric correction performance, and view sun angle geometries, resulting in nonbiological artifacts and noise in the VI values (Huete et al., 2011). Therefore many researchers have tried to denoise the MODIS VI data.

Jennifer and McDermid (2009) compared six NDVI time series noise-reduction techniques, and found that the asymmetric Gaussian, Double logistic, and $4253 \mathrm{H}$ twice filter perform very well in general. As the EVI tends to have less negatively-biased noise and more erroneous spikes than the NDVI, in which case noise-reduction techniques maintaining the upper envelope of values such as the double logistic and asymmetric Gaussian function fitting techniques may not be the most effective choice (Jennifer and McDermid, 2009) whereas $4253 \mathrm{H}$ twice filter has the ability of eliminating spurious drops and spikes (Velleman, 1980), we tried to apply the $4253 \mathrm{H}$ twice filter to reduce the noise in EVI time series. Figure 5 shows the denoising effect with $4253 \mathrm{H}$ twice filter, which applies a series of running medians of varying temporal window size and a weighted average filter (e.g., Hanning filter), with re-roughing, to the EVI time series at a randomly selected pixel in WGEW over about one year. From Fig. 5 we see that both low values and high values are smoothed with $4253 \mathrm{H}$ twice filter.

While it works with the noise-reduction techniques, it is possible that the application of these techniques might be causing a lost of valid information because the fluctuation of EVI may be related to soil moisture changes. For instance, Wang et al. (2007) found that, in growing seasons, the lag time for NDVI to respond to soil moisture change is about 5 days or less at the semi-arid sites, and 10 days at the humid site. Because MODIS vegetation index product is 16-day composite data and our study area in an arid zone, the effects of soil moisture change should be reflected in the EVI products. Therefore, we decide to skip the denoising procedure, using the original EVI product instead.

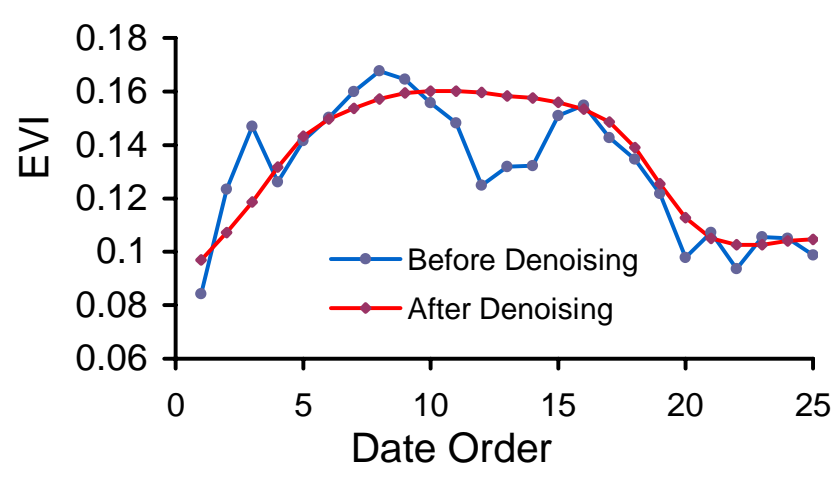

Fig. 5. Effects of EVI denoising preprocessing for a randomly selected pixel (Note: numbers of the horizontal axis indicate the 25 consecutive 16-day composite data sets starting from the last dataset in 2003 to the first one in 2005).

\subsection{Topographic correction of air temperature}

With methods of estimating soil moisture using thermal satellite images, often both land surface temperature and ground-based air temperature observations are needed. When applying such methods to mountainous regions, terrain effects have to be taken into account because terrain would significantly affect both land surface temperature and air temperature. To avoid the problem of steeply sloping terrain, some authors just eliminated those pixels in mountainous part (e.g., Carlson et al., 1994), while in some other cases, land surface temperature was corrected (e.g., Hassan et al., 2007). In the present study, we go the opposite way, i.e., instead of correcting land surface temperature, we correct the air temperature.

To make a successful air temperature interpolation, many factors should be taken into account, such as the elevation difference between a pixel and monitoring stations, temperature vertical gradient, geometric characteristics (slope, aspect) of each pixel cell, and vegetation coverage. Moore et al. (1993) proposed a specific algorithm to calculate daytime temperature at different altitudes within a valley. Based on that, Bellasio et al. (2005) proposed a simplified equation in the form of

$T_{i}=T_{b}-\beta\left(z_{p}-z_{0}\right)+C\left(S_{i}-1 / S_{i}\right)\left(1-\mathrm{LAI}_{i} / \mathrm{LAI}_{\max }\right)$

where $T_{i}$ is the unknown atmospheric temperature $(\mathrm{K})$ at a $z_{i}$ altitude $(\mathrm{m}), T_{b}$ is the measured atmospheric temperature $(\mathrm{K})$ at a $z_{b}$ altitude $(\mathrm{m}), \beta$ is the vertical temperature gradient $\left(\mathrm{K} \mathrm{m}^{-1}\right), C$ is a constant, $\mathrm{LAI}_{\max }$ and $\mathrm{LAI}_{i}$ are, respectively, maximum leaf area index (LAI) and its value at $z_{i}$, and $S_{i}$ is the ratio between direct shortwave radiation on the actual surface (with its slope and aspect) and direct shortwave radiation on a horizontal free surface.

The above equation did not consider the impacts of wind. But according to the research of McCutchan and Fox (1986), for their study area (an isolated, conical mountain with elevation ranging from 2743 to $3324 \mathrm{~m}$ ), wind speeds greater 

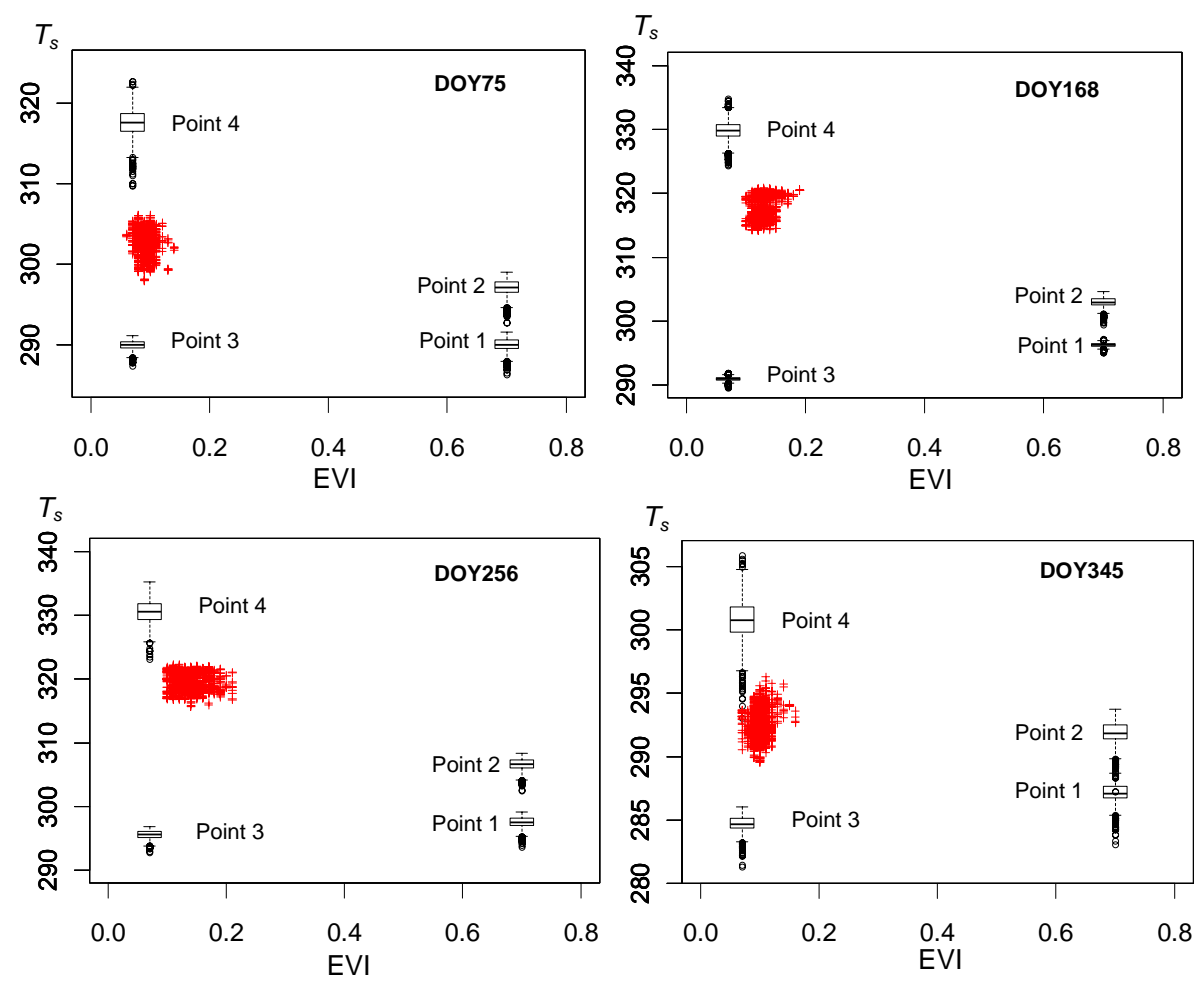

Fig. 6. Constructed $T_{\mathrm{S}} \sim$ EVI trapezoids in four dates (DOY $=75,168,256$ and 345 in 2004).

than $5 \mathrm{~m} \mathrm{~s}^{-1}$ negate any slope, elevation or aspect effects that are present at low wind speed. We approximate this wind effect with a coefficient $e^{-u / 3}\left(u\right.$ is the wind speed, $\left.\mathrm{m} \mathrm{s}^{-1}\right)$, in consequence, we obtain a modified equation of Eq. (17) as

$T_{i}=T_{\mathrm{b}}-\beta\left(z_{i}-z_{0}\right)+C e^{-u / 3}\left(S_{i}-1 / S_{i}\right)\left(1-\mathrm{LAI}_{i} / \mathrm{LAI}_{\max }\right)$

Therefore, when there are air temperature observations at several sites, we can conduct air temperature correction in the following three steps:

1. Correct the observations to a flat plane at a base level All the temperature data are corrected to a flat plane at a base level (the lowest elevation $z_{0}$ of the observation sites), considering the effects of not only the elevation difference, but also the effects of wind, slope, and aspect. This is basically a reverse correction of Eq. (18), i.e.,

$$
\begin{array}{r}
T_{\mathrm{a}, \mathrm{b}}^{(i)}=T_{\mathrm{a}}^{(i)}+\beta\left(z_{i}-z_{0}\right)-C e^{-u / 3} \\
\left(S_{i}-1 / S_{i}\right)\left(1-\mathrm{LAI}_{i} / \mathrm{LAI}_{\mathrm{max}}\right)
\end{array}
$$

where $T_{\mathrm{a}, \mathrm{b}}^{(i)}$ is the temperature observation corrected to the base level at site $i, \beta$ is the temperature lapse rate $\left(\mathrm{K} \mathrm{m}^{-1}\right), z_{i}$ is the elevation of site $i$, and $z_{0}$ is the elevation of the base level (m).
2. Interpolate temperature for each pixel $p$ using observations on the flat plane at the base level

Use the corrected air temperature observations $T_{\mathrm{a}, \mathrm{b}}^{(i)}$ to interpolate the air temperature for all pixels with a spatial interpolation method (e.g., the inverse distance weighting interpolation method) to get interpolated air temperature $T_{\mathrm{a}, \mathrm{I}}^{\mathrm{p}}$ for each pixel $p$ on the flat plane at the base level.

3. Topographic correction for each pixel $p$ to its real position using Eq. (18), where $T_{\mathrm{b}}$ is replaced by $T_{\mathrm{a}, \mathrm{I}}^{\mathrm{p}}$. Bellasio et al. (2005) suggested to set $\mathrm{LAI}_{\max }=10$. As values of LAI of various vegetation types are mostly less than 8 (Scurlock et al., 2001), here for the arid zone WGEW we set $\mathrm{LAI}_{\text {max }}=8, C=2$ and $\beta=0.0065 \mathrm{~K} \mathrm{~m}^{-1}$. $\beta=0.0065 \mathrm{~K} \mathrm{~m}^{-1}$ represents a long term average. It would be better to investigate the air temperature difference at sites of difference elevation to derive an accurate dynamic short-term estimate of $\beta$ for a specific area. But the value of 0.0065 could be a reasonable estimate when not enough observations with different elevations are available to make a more accurate estimate. 

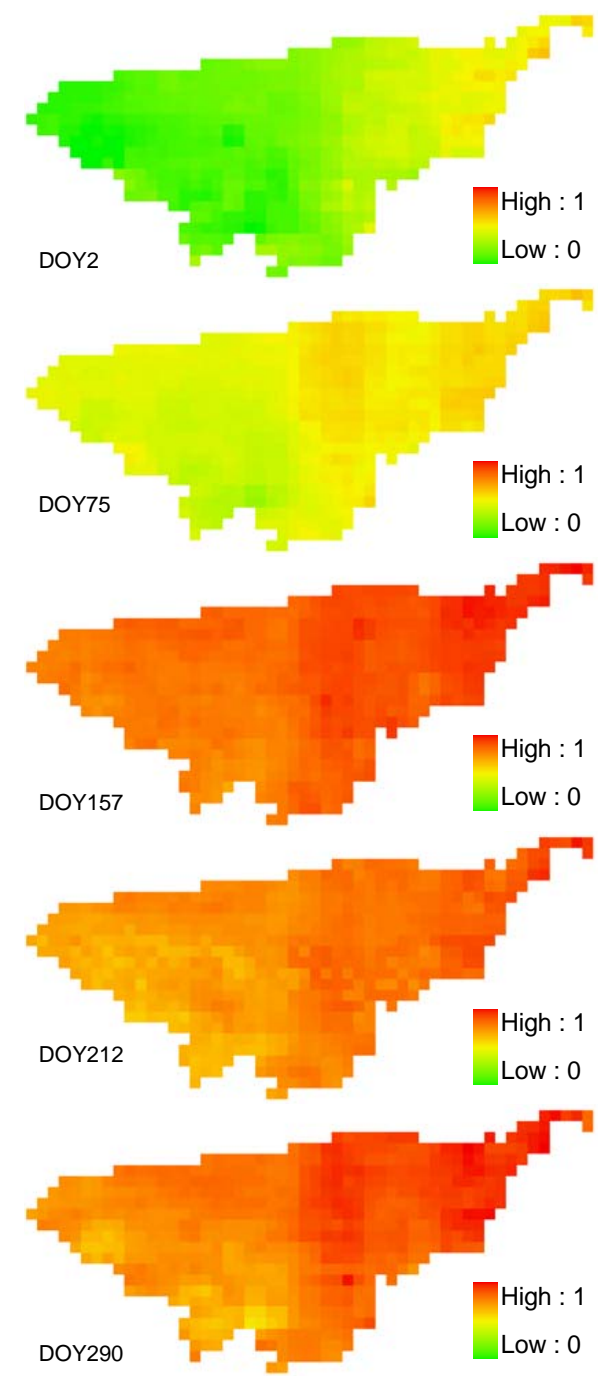

Fig. 7. WDI maps in 10 DOYs in 2004 for WGEW.

\section{Application of $T_{\mathrm{s}} \sim$ VI trapezoid method to WGEW}

\subsection{Constructing $T_{\mathrm{s}} \sim$ VI trapezoids}

A reasonable shape of the trapezoid is the essence of all the algorithms based on the $T_{\mathrm{S}} \sim$ VI relationship for estimating soil moisture. When implementing the algorithm described in Sect. 2, two parameters, i.e., $S_{k B}$ and $G / R_{\mathrm{n}}$, were set by trial and error. For the case study area WGEW, we set $S_{k B}$ to be 0.1 for both vegetated points (point 1 and 2) and bare soil points (point 3 and 4 ), $G / R_{\mathrm{n}}$ to be 0.3 for wet bare soil, 0.4 for dry bare soil, and 0.05 for full vegetation surfaces. As invested by Huete et al. (2011), the MODIS EVI values varied from 0.07 to $\sim 0.7$ for major land cover types from hyperarid deserts to dense forests at $1-\mathrm{km}$ resolution, we set the minimum and maximum EVI values to be 0.07 and 0.7 when constructing $T_{\mathrm{s}} \sim \mathrm{VI}$ trapezoids.

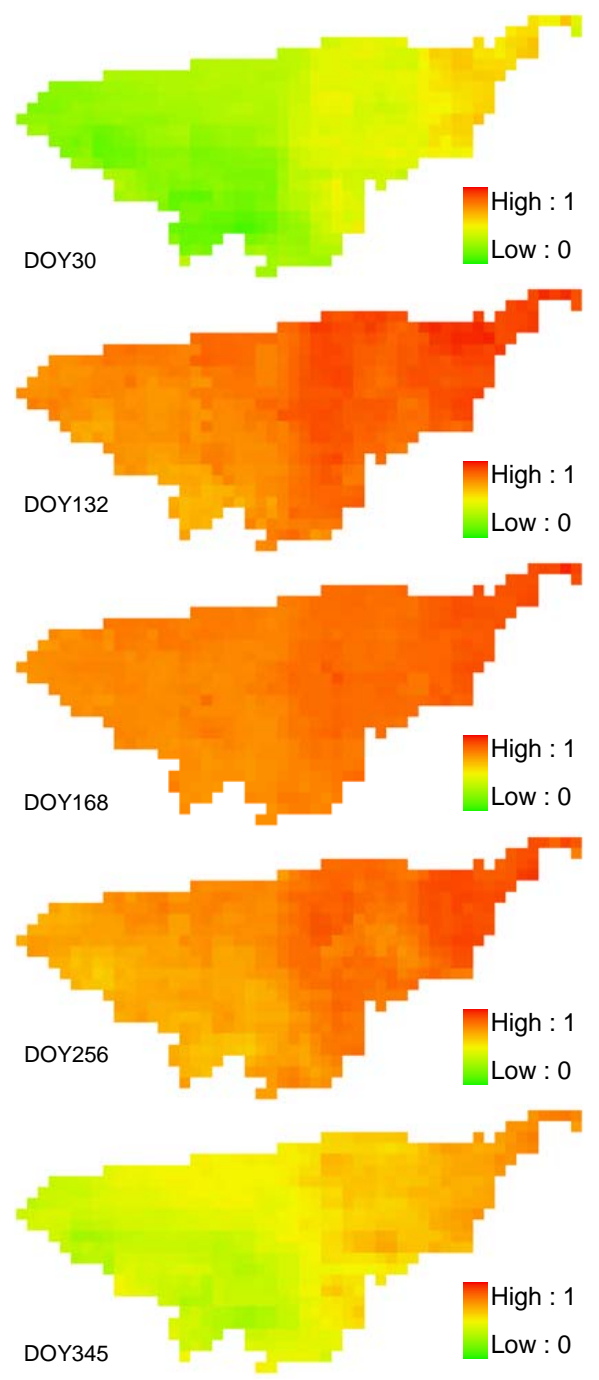

To show the effectiveness of the calculation for the values of $T_{\mathrm{S}}$ of four vertices, we plot the four vertices of the trapezoids constructed for all the pixels of the WGEW region in four days in four seasons in Fig. 6. All the estimated $T_{\mathrm{S}}$ at each point are plotted in the form of box-and-whisker plot. The data points (solid dots) of $T_{\mathrm{s}}$ vs. EVI are also plotted in the map. From Fig. 6, we see that the constructed trapezoids well characterize the $T_{\mathrm{s}} \sim$ EVI space, and basically all the $T_{\mathrm{S}} \sim$ EVI data points are set in the envelope of the trapezoids.

\subsection{Calculation of WDI}

Based on the constructed $T_{\mathrm{s}} \sim \mathrm{VI}$ trapezoid for each pixel, using the MODIS land surface temperature and EVI data, we calculate the WDI for each pixel $p$, 


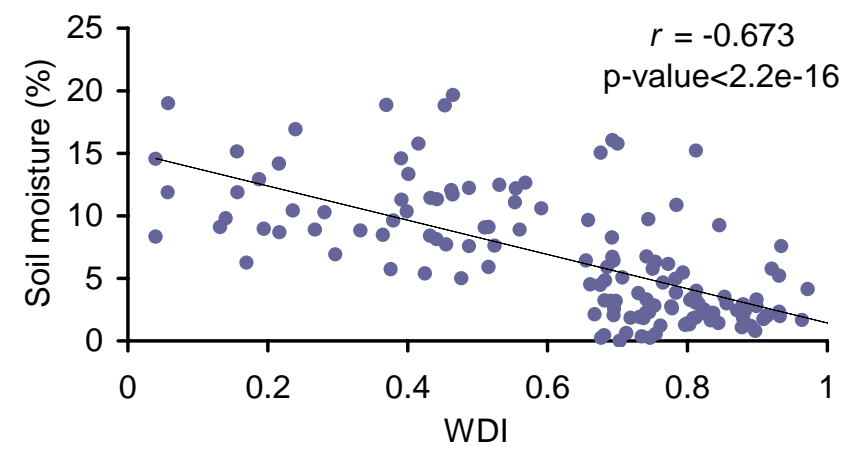

Fig. 8. WDI estimates vs. ground observations at 16 sites in 10 dates. (Note: $r$ is the correlation coefficient. The $p$-value is the t-test result for testing significance of the correlation coefficient. The null hypothesis is: correlation coefficient $=0$. A $p$-value of less than 0.05 indicates significant correlation at a 0.05 significance level.)

$\mathrm{WDI}^{(\mathrm{p})}=\frac{T_{\mathrm{s}}^{(\mathrm{p})}-T_{\mathrm{s}, \min }^{(\mathrm{p})}}{T_{\mathrm{s}, \text { min }}^{(\mathrm{p})}-T_{\mathrm{s}, \max }^{(\mathrm{p})}}$

where $T_{\mathrm{s}}$ is surface temperature obtained from MODIS; the subscripts min and max refer to minimum and maximum values; and the minimum and maximum values of $T_{\mathrm{s}}$ are interpolated linearly on the dry edge and wet edge of the $T_{\mathrm{S}} \sim \mathrm{VI}$ trapezoid based on the $T_{\mathrm{S}}$ values calculated at four vertices for the specific VI value of the pixel $p$.

The WDI maps in ten DOYs for WGEW are illustrated in Fig. 7.

\subsection{Comparison with soil moisture observation and precipitation}

Using the surface soil moisture observations at 16 sites in 10 dates, we evaluate WDI estimates in several ways: (1) compared WDI estimates with ground observations of each site in 10 dates (Fig. 8); (2) compare the average of WDI estimates with the average ground observations of all sites in 10 dates (Fig. 9); (3) compare the WDI estimates with ground observations of all sites in each date (Table 3).

From the scatter plot of WDI vs. soil moisture observation in Fig. 8, we see that from the perspective of a whole year, WDI estimates derived with the $T_{\mathrm{s}} \sim \mathrm{VI}$ trapezoid method has a negative correlation (correlation coefficient $r=-0.673$ ) with surface soil moisture, which indicates that WDI estimates can be used to detect the temporal variation in soil moisture. Especially on the scale of the watershed, the average WDI is strongly negatively related (correlation coefficient $r=-0.924$ ) to the average soil moisture observation, as shown in Fig. 9. Similar phenomena have been observed by some other researchers as well. For instance, Pellenq et al. (2003) noticed that the point-to-point comparison between observations and simulations shows a poor correlation,

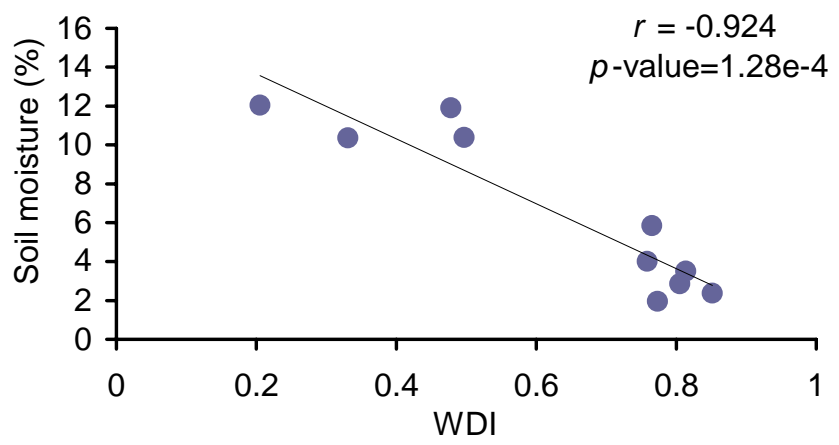

Fig. 9. The average WDI estimates vs. the average ground observations in 10 dates. (Meanings of $r$ and $p$-value are the same as in Fig. 8.)

but a good correlation is obtained when averaging the simulated and observed soil moisture over a length of $100 \mathrm{~m}$.

The comparison between the WDI estimates with ground observations of each date (Table 3 ) shows that there is basically no correlation between WDI estimates and surface soil moisture observations. This is partly because of the scale effect, i.e., point soil moisture observations are essentially different from pixel averaged soil moisture estimates due to sub pixel variability, partly due to the lower spatial variability than the temporal variability in soil moisture that makes it more difficult in using WDI to detect the spatial variation than to detect the temporal variation. Comparing the statistics of soil moisture observations in Table 2, we see that the average Coefficient of Variation (CV) for soil moisture observations at 16 sites in the 10 DOYs is 0.732 (ranging from 0.429 to 1.187 ), much larger than the average $\mathrm{CV}$, 0.510 , for observed soil moisture in any given date (ranging from 0.325 to 0.677 ). In consequence, we can use WDI to detect the temporal variation in soil moisture, but it seems that it would be hard to detect spatial variation in a day, especially for a small watershed with low spatial soil moisture variability at the $500 \mathrm{~m}$ pixel scale.

Despite of the poor performance for characterizing the spatial variability of soil moisture with WDI, by a visual inspection of the WDI maps of the WGEW region of the 10 dates in Fig. 7, we can still see a clear spatial pattern of soil moisture distribution, which indicates that, to some extent, soil moisture variability could be depicted by WDI maps.

We analyzed the impacts of precipitation on soil moisture by calculating the correlation between WDI and Antecedent Precipitation (AP) of different number of days, and between soil moisture observation and AP of different number of days. The results are illustrated in Fig. 10, which show that WDI and soil moisture observation have similar levels of correlation with AP (one is positive, another is negative), and the maximum correlation occurs when approximately 10-day AP is taken into account. The scatter plot is shown in Fig. 11. The result indicates that, as expected, the temporal variation 
Table 3. Correlation between WDI estimates with surface soil moisture observations.

\begin{tabular}{llrrrrrrrrr}
\hline DOY & \multicolumn{1}{c}{2} & \multicolumn{1}{c}{30} & \multicolumn{1}{c}{75} & 132 & \multicolumn{1}{c}{157} & 168 & 212 & 256 & \multicolumn{1}{c}{290} & 345 \\
\hline$r$ & 0 & -0.288 & -0.0316 & 0.045 & -0.309 & 0 & -0.612 & -0.567 & 0.376 & -0.114 \\
$p$-value & 0.523 & 0.808 & 0.586 & 0.870 & 0.261 & 0.946 & 0.015 & 0.027 & 0.186 & 0.955 \\
\hline
\end{tabular}

Note: Meanings of $r$ and $p$-value are the same as in Fig. 8.
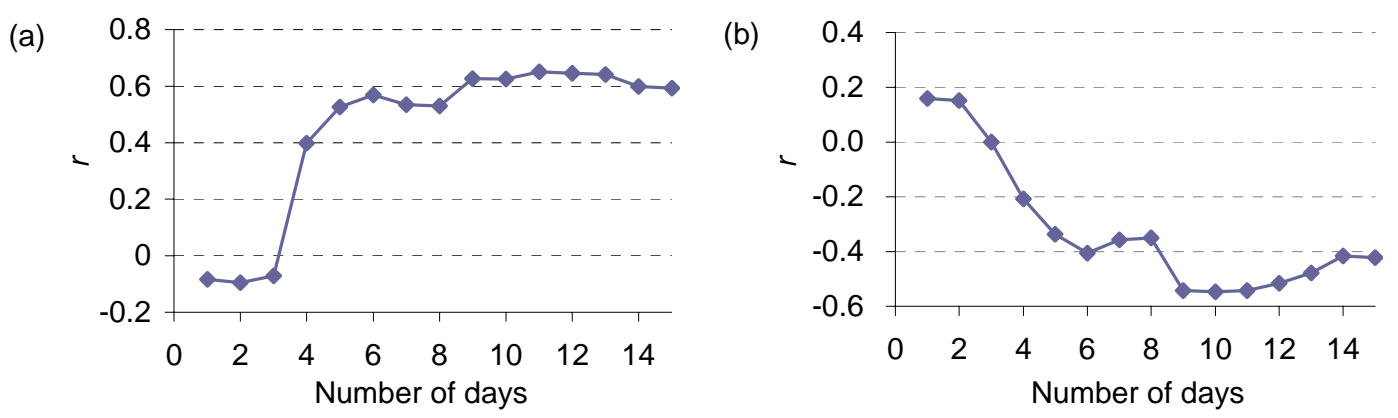

Fig. 10. Correlation coefficient $(r)$ between (a) soil moisture observation and AP of different number of days, and (b) WDI and AP of different number of days.
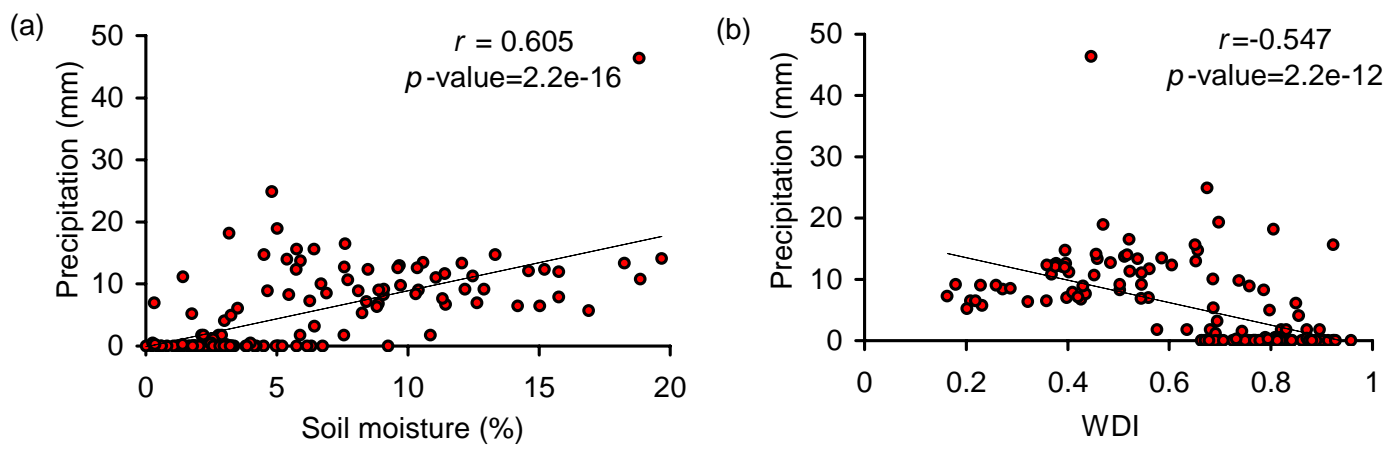

Fig. 11. Scatter plot of (a) soil moisture observation and (b) WDI vs. 10-day AP ( $r$ is the coefficient of correlation).

of soil moisture (either reflected by ground observations, or by WDI estimates) is significantly dominated by precipitation process.

\section{Conclusions}

Considerable efforts have been put on using the relationship between surface temperature and vegetation index $\left(T_{\mathrm{S}} \sim \mathrm{VI}\right)$ to estimate surface soil moisture in the last two decades. Since the publication of the paper by Moran et al. (1994), where they defined the trapezoidal relationship between the surface temperature and air temperature difference $\left(T_{\mathrm{S}}-T_{\mathrm{a}}\right)$ vs. the fractional vegetation cover $\left(V_{C}\right)$, the shape of trapezoid has been commonly accepted as one of the ways of characterizing the $T_{\mathrm{s}} \sim$ VI relationship. However, in the algorithm proposed by Moran et al. (1994), when they calculated the value of $T_{\mathrm{s}}-T_{\mathrm{a}}$, no consideration was taken about the feedback effect of changes in $T_{\mathrm{S}}-T_{\mathrm{a}}$ on some variables such as $r_{\mathrm{a}}$ and $R_{\mathrm{n}}$ which are used in the calculation of $T_{\mathrm{s}}-T_{\mathrm{a}}$. In addition, there is a problem of applying the method for areas with complex terrains and limited availability of ground meteorological observations. In the present study, we simplified the $T_{\mathrm{s}}-T_{\mathrm{a}}$ versus $V_{\mathrm{C}}$ trapezoid to the $T_{\mathrm{s}} \sim \mathrm{VI}$ trapezoid for each pixel, and proposed an algorithm to iteratively update the values of quantities such as $R_{\mathrm{n}}$ and $r_{\mathrm{a}}$ so to keep the $T_{\mathrm{s}}$ changing until it reaches a stable value. Then the Water Deficit Index (WDI) is calculated for each pixel based on the location of the data point of MODIS remotely sensed surface temperature versus Enhanced Vegetation Index (EVI) in the $T_{\mathrm{s}} \sim$ VI trapezoid.

Using ground-based observations at the Walnut Gulch Experimental Watershed (WGEW) in Arizona, USA, the capability of using WDI to estimate soil moisture is evaluated by comparing it with soil moisture observations and antecedent precipitation. The result shows that, $T_{\mathrm{S}} \sim \mathrm{VI}$ trapezoid based 
WDI can well capture temporal variation in surface soil moisture, but the capability of detecting spatial variation is poor for such a semi-arid region as WGEW.

The advantages of the $T_{\mathrm{S}} \sim \mathrm{VI}$ trapezoid method include: (1) in comparison with the triangle method, which sets the dry and wet edges empirically, the trapezoid method determines the dry and wet edges based on a solid physical background, and hence, the WDI values for different periods are comparable, which makes WDI an appropriate index for monitoring the temporal change in soil moisture; (2) the method is applicable for even a small region with a narrow range of soil wetness and fractional vegetation cover, which is not possible with commonly used methods such as the triangle method or the SEBAL model (Bastiaanssen et al., 1998).

There are some limitations of the $T_{\mathrm{S}} \sim \mathrm{VI}$ trapezoid method as well, including: (1) the method requires groundbased data, which restricts its use in areas where groundbased meteorological data (i.e., air temperature, wind speed, relative humidity) are poor or not available. For areas with poor to no data coverage, we have to either use limited observations to do interpolation, or take advantage of regional climate model such as the Weather Research and Forecasting (WRF) Model (http://www.wrf-model.org/). (2) Some parameters, including those seem to be sensitive, such as $S_{k B}$ for calculating $k B^{-1}$, were determined empirically or by a trial and error procedure. In addition, the albedo values for four vertices should be different due to the difference of land surface, but here they are considered identical as that provided by the MODIS MCD43 product because of the difficulty in quantitatively describing the difference. These are topics for future research.

Acknowledgements. We are very grateful to three anonymous reviewers for their very constructive comments which significantly improved the manuscript. Many thanks to USDA Southwest Watershed Research Center for making the observation data of the Walnut Gulch Experimental Watershed freely available to the public. The financial supports from the National Science Foundation of China (40771039, 40930635), China Postdoctoral Science Foundation (20080431062) and the 111 Project (B08048) are gratefully acknowledged.

Edited by: N. Verhoest

\section{References}

Bastiaanssen, W. G. M., Menenti, M., Feddes, R. A., and Holtslag, A. A. M.: A remote sensing surface energy balance algorithm for land (SEBAL) 1. Formulation, J. Hydrol., 212, 198-212, 1998.

Bellasio, R., Maffeis, G., Scire, J. S., Longoni, M. G., Bianconi, R., and Quaranta, N.: Algorithms to Account for Topographic Shading Effects and Surface Temperature Dependence on Terrain Elevation in Diagnostic Meteorological Models, Bound.-Lay. Meteorol., 114, 595-614, 2005.
Brutsaert, W.: Hydrology: An introduction, Cambridge Univeristy Press, New York, 57-70, 2005.

Carlson, T. N., Gillies, R. R., and Perry, E. M.: A method to make use of thermal infrared temperature and NDVI measurements to infer surface soil water content and fractional vegetation cover, Remote Sens. Rev., 9, 161-173, 1994.

Carlson, T.: An overview of the "Triangle Method" for Estimating Surface Evapotranspiration and Soil Moisture from Satellite Imagery, Sensors, 7, 1612-1629, 2007.

Choudhury, B. J., Idso, S. B., and Reginato, R. J.: Analysis of an empirical model for soil heat flux under a growing wheat crop for estimating evaporation by an infrared-temperature based energy balance equation, Agr. Forest Meteorol., 39, 283-297, 1987.

Duffie, J. A. and Beckman, W. A.: Solar engineering of thermal process (2nd edition), John Wiley and Sons, NY, 1991.

Garratt, J. R.: The Atmospheric Boundary Layer, Cambridge University Press, New York, 316 pp., 1992.

Goward, S. N., Cruickhanks, G. D., and Hope, A. S.: Observed relation between thermal emission and reflected spectral radiance of a complex vegetated landscape, Remote Sens. Environ., 18, 137-146, 1985.

Hassan, Q. K., Bourque, C. P. A., Meng, F. R., and Cox, R. M.: A wetness index using terrain-corrected surface temperature and normalized difference vegetation index derived from standard MODIS products: An evaluation of its use in a humid forestdominated region of eastern Canada, Sensors, 7, 2028-2048, 2007.

Huete, A., Didan, K., van Leeuwen, W., Miura, T., and Glenn, E.: Chapter 26 MODIS Vegetation Indices, in: Land Remote Sensing and Global Environmental Change, edited by: Ramachandran, B., Justice, C. O., and Abrams, M. J., Springer, New York, 579-602, 2011.

Idso, S. B., Aase, J. K., and Jackson, R. D.: Net radiation - Soil heat flux relations as influenced by soil water content variations, Bound.-Lay. Meteorol., 9, 113-122, 1975.

Idso, S. B., Jackson, R. D., Pinter Jr., P. J., Reginato, R. J., and Hatfield, J. L.: Normalizing the stress-degree-day parameter for environmental variability, Agr. Meteorol., 24, 45-55, 1981.

Iziomon, M. G., Mayer, H., and Matzarakis, A.: Downward atmospheric longwave irradiance under clear and cloudy skies: Measurement and parameterization, J. Atmos. Sol.-Terr. Phy., 65, 1107-1116, 2003.

Jackson, R. D., Idso, S. B. Reginato, R. J., and Pinter, P. J.: Canopy temperature as a crop water stress indicator, Water Resour. Res., 17, 1133-1138, 1981.

Jennifer, N. H. and McDermid, G. J.: Noise reduction of NDVI time series: An empirical comparison of selected techniques, Remote Sens. Environ., 113, 248-258, 2009.

Kustas, W. P. and Norman, J. M.: Use of remote sensing for evapotranspiration monitoring over land surfaces, Hydrolog. Sci. J., 41, 495-516, 1996.

Kustas, W. P., Choudhury, B. J., Moran, M. S., Reginato, R. J., Jackson, R. D., Gay, L. W., and Weaver, H. L.: Determination of sensible heat flux over sparse canopy using thermal infrared data, Agr. Forest Meteorol., 44(3-4), 197-216, 1989.

Liu, H. Q. and Huete, A.: A feedback based modification of the NDVI to minimize canopy background and atmospheric noise, IEEE T. Geosci. Remote, 33, 457-465, 1995. 
McCutchan, M. H. and Fox, D. G.: Effect of Elevation and Aspect on Wind,Temperature and Humidity, J. Clim. Appl. Meteorol., 25(12), 1996-2013, 1986.

Monteith, J. and Unsworth, M.: Principles of environmental physics, 3rd edition, Academic Press, Boston, 2008.

Monin, A. S. and Obukhov, A. M.: Basic laws of turbulent mixing in the surface layer of the atmosphere, Tr. Akad. Nauk SSSR Geofiz. Inst., 24, 163-187, 1954.

Moore, I. D., Norton, T. W., and Williams, J. E.: Modeling Environmental Heterogeneity in Forested Landscapes, J. Hydrol., 150, 717-747, 1993.

Moran, M. S., Clarke, T. R., Inoue, Y., and Vidal, A.: Estimating crop water deficit using the relation between surface air temperature and spectral vegetation index, Remote Sens. Environ., 49, 246-263, 1994.

Nemani, R. R. and Running, S. W.: Estimation of regional surface resistance to evapotranspiration from NDVI and thermal IR AVHRR data, J. Appl. Meteorol., 28, 276-284, 1989.

Nemani, R. R., Pierce, L., Running, S. W., and Goward, S.: Developing satellite-derived estimates of surface moisture status, J. Appl. Meteorol., 32, 548-557, 1993.

Paulson, C. A.: The mathematical representation of wind speed and temperature profiles in the unstable atmospheric surface layer, J. Appl. Meteorol., 9, 857-861, 1970.

Pellenq, J., Kalma, J., Boulet, G., Saulnier, G. M., Wooldridge, S., Kerr, Y., and Chehbouni, A.: A disaggregation scheme for soil moisture based on topography and soil depth, J. Hydrol., 276, 112-127, 2003.

Price, J. C.: Using spatial context in satellite data to infer regional scale evapotranspiration, IEEE T. Geosci. Remote, 28, 940-948, 1990.

Renard, K. G., Lane, L. J., Simanton, J. R., Emmerich, W. E., Stone, J. J., Weltz, M. A., Goodrich, D. C., and Yakowitz, D. S.: Agricultural impacts in an arid environment: Walnut Gulch case study, Hydrol. Sci. Technol., 9(1-4), 145-190, 1993.
Scurlock, J. M. O., Asner, G. P., and Gower, S. T.: Global Leaf Area Index Data from Field Measurements, 1932-2000, Data set, available on-line: http://www.daac.ornl.gov from the Oak Ridge National Laboratory Distributed Active Archive Center, Oak Ridge, Tennessee, USA, 2001.

Shuttleworth, W. and Wallace, J.: Evaporation from Sparse Crops An Energy Combination Theory, Q. J. Roy. Meteorol. Soc., 111, 839-855, 1985.

Smith, R. C. G. and Choudhury, B. J.: Analysis of normalized difference and surface temperature observations over southeastern Australia, Int. J. Remote Sens., 12(10), 2021-2044, 1991.

Snyder, W. C., Wan, Z., Zhang, Y., and Feng, Y.-Z.: Classificationbased emissivity for land surface temperature measurement from space, Int. J. Remote Sens., 19(14), 2753-2774, 1998.

Thom, A. S.: Momentum, mass and heat exchange of plant communities, in: Vegetation and the Atmosphere, edited by: Monteith, J. L., Academic Press, London, 57-109, 1975.

Velleman, P.: Definition and comparison of robust nonlinear data smoothing algorithms, J. Am. Stat. Assoc., 75, 609-615, 1980.

Wang, X. W., Xie, H. J., Guan, H. D., and Zhou, X. B. Different responses of MODIS derived NDVI to root-zone soil moisture in semi-arid and humid regions, J. Hydrol., 340(1-2), 12-24, 2007.

Webb, E. K.: Profile relationships: The log-linear range, and extension to strong stability, Q. J. Roy. Meteorol. Soc., 96, 67-90, 1970.

WMO - World Meteorological Organization: Guide to Meteorological Instruments and Methods of Observation, WMO-No. 8 (CIMO Guide), Geneva, 2008.

Zillman, J. W.: A study of some aspects of the radiation and heat budgets of the southern hemisphere oceans, Australian Government Publishing Service, Canberra, 1972. 